\title{
Characterising food insecurity in pastoral and agro-pastoral communities in Uganda using a consumption coping strategy index
}

Maureen N. Mayanja ${ }^{1 *}$, Chris Rubaire-Akiiki ${ }^{2,3}$, Ted Greiner ${ }^{4}$ and John F. Morton ${ }^{5}$

\begin{abstract}
We explore the utility of a consumption coping strategy index (CSI) in characterising and assessing the factors influencing household food insecurity. We assessed 53 pastoral and 197 agro-pastoral households in Nakasongola and Nakaseke districts of Uganda, examining the use of 27 consumption coping strategies over a recall time of two 30-day periods, one at the start of a dry season in 2012 and one at the start of a rainy season in 2013.

Four categorical food insecurity status measures were established - food secure (CSI 0 to 5) and mildly (CSI 6 to 20), moderately (CSI 21 to 42) and extremely (CSI >42) food insecure. For the dry season, the mean CSI was $29.4 \pm 2.59$ and $33.6 \%$ of households were food secure, while for the rains, mean CSI was $33.1 \pm 2.30$ and $14.0 \%$ of households were food secure. The combination of livelihood system, land holdings, number of livestock owned and belonging to a social network explained $9.4 \%$ to $10 \%$ of the variance in household food insecurity for agro-pastoralists, but variance for pastoralists was not explained by these factors. While the only highly significant factor associated with increasing household food insecurity in the dry season was low landholdings, in the rainy season, it was pastoral livelihood, low livestock holdings for agro-pastoralists and non-involvement in social networks.

While our model identified a number of factors important in describing household food insecurity, it explained only about $10 \%$ of the variance.
\end{abstract}

Keywords: Food insecurity; Consumption coping strategies; Pastoral households; Tropical livestock units

\section{Background}

The term 'food insecurity' is applied to a wide range of phenomena, from famine to periodic hunger to uncertain food supply (FAO 2003). According to FAO (2002), at any moment in time an individual can be:

- food secure (adequate food intake, low risk of food insecurity);

- vulnerable (adequate food intake, high risk of food insecurity); or

- food insecure (inadequate food intake, high risk of worsening food insecurity).

\footnotetext{
* Correspondence: mayanja66@yahoo.com

${ }^{1}$ Dept of Biosecurity, Ecosystem and Veterinary Public Health, College of Veterinary Medicine, Animal Resources and Biosecurity, Makerere University, P.O. Box 7062, Kampala, Uganda
}

Full list of author information is available at the end of the article
Much food security analysis has moved beyond just looking at availability or access and is now grounded in a solid understanding of livelihoods (Maxwell et al. 2008b). Inclusion of more subjective perceptions of the problem as well as livelihood capacities and strategies in the measurement of food insecurity at the household level was suggested by Maxwell, 1996 (cited in Maxwell et al. (1999). For example, food consumption coping strategies (CCS) are behaviours which people in a given population adopt, when there is insufficient food in the household and insufficient money to buy food (Maxwell et al. 1999; Maxwell et al. 2003). When CCS are weighted for the severity of the circumstances in which they are used, as perceived by the community, and combined with frequency of use by a household, they result in a simple quantitative score - the coping strategy index (CSI). The CSI is suited to a rural-based community since it is simple, straightforward to understand and sensitive to short-term changes such as seasonality and shocks, however major or minor (Maxwell et al. 2003). Compared to 
the more traditional consumption, poverty and nutritional proxy measures, coping strategy indicators are best at minimising the risk of classifying a food insecure household as food secure; they also identify sources of vulnerability (Maxwell et al. 1999). Although not an absolute measure, the CSI establishes a baseline, within-sample, comparative measure from which changes in food security among households can be monitored over time (Maxwell et al. 2003). The CSI has also been mentioned as one of the indicators of food access in addition to the household asset index and diet diversity (Renzaho and Mellor 2009). It is distinct in that it queries household behaviours directly and factors in the severity of different behaviours (Maxwell et al. 2008a). It is therefore an approach factoring in severity of household coping behaviours based on people's own perceptions and a comparative measure that can monitor changes among households,

Based on the poverty and hunger index, as a measure of food insecurity and humanitarian need, Uganda was at one time ranked seventh out of the top 10 worst cases (Maxwell et al. 2008b). After the prolonged drought of $1999 / 2000$, the cattle corridor of Uganda and specifically Nakasongola and Nakaseke districts, which are the target of this study, experienced failed harvests, outbreaks of crop and animal diseases, and poor health conditions, leaving many vulnerable to food insecurity (NAPA 2007). Yet as far as we know, no research has explored the dimensions of food security in either of these districts or the country as a whole now comparing pastoral and agro-pastoral groups. This study explores utility of the consumption CSI in describing the relative prevalence of household food insecurity and assesses the factors influencing it in pastoral and agro-pastoral communities in two different seasons.

\section{Study area}

The cattle corridor of Uganda is a strip of rangelands with an estimated area of $84,000 \mathrm{~km}^{2}$ (43\% of the country's total land area) and is predominantly a pastoralist and agro-pastoralist region. The study area, Nakasongola and Nakaseke districts, is in the central part of this cattle corridor and according to a livelihood zoning exercise done in Uganda in 2009 is in the central and southern cattle cassava maize zone (FEWSNET 2010). This zone is sparsely populated and its economy is driven by rainfed agricultural and livestock husbandry. The districts lie in a transition zone between areas with a clear bimodal rainfall in the south and areas with a unimodal rainfall in the north. In the period 2001 to 2010, the mean total seasonal rainfall for March to May (MAM) was $420.6 \mathrm{~mm}$, and for September to November (SON), it was $397.6 \mathrm{~mm}$ (Nimusiima et al. 2013). Over the period 1961 to 2010, the number of dry spells within a rainfall season had increased with the most significant increase observed in the first rainfall season of MAM as compared to the SON season (Nimusiima et al. 2013).

Nakasongola and Nakaseke districts have a mix of ethnic groups including Baruuli, Banyankore and Baganda. The population has been described thus:

'...though better-off households are capable of producing more crops than their poorer neighbours they too are unable to produce all of their annual food needs. They therefore must buy most of their food complimenting it with their own production (livestock products and crops). In addition, all but the very wealthiest pastoralists do not own enough animals to solely rely on milk and meat, and so their economy is based on the premise of exchange and sale of livestock and livestock products for grain and other necessities via the market' (FEWSNET 2010).

Prolonged dry spells are the most common hazard affecting agricultural production and livestock ground water supplies and pastures, and the typical response strategy for households in this area is to sell additional livestock and rely more on purchased foods (FEWSNET 2010).

\section{Methodology \\ Design of the study}

We carried out a comparative, cross-sectional study involving collection of qualitative and quantitative data to coincide with two climatic seasons. The first household survey was carried out at the start of the first of the two annual dry seasons, over a period of five weeks from mid-July to mid-August 2012, while the second one was done over a period of two weeks from the beginning of mid-February 2013, which was an early start of the first rainy season. Following the procedure recommended by Maxwell et al. (2003), the current study used qualitative methods to develop a list of 27 CCS and the level of severity of food insecurity they represent in the context of the studied communities and then used quantitative methods to develop a CSI for each household.

\section{Sampling of survey respondents}

The study followed a multistage sampling process using both random and purposive techniques to select from a sample frame of villages that had been previously randomly selected for another survey in the study area (see Appendix 1 for that sampling process). In the first stage, we selected two strata with 60 villages each, a pastoral stratum dominated by a livestock (cattle) extensive farming system and an agro-pastoral stratum dominated by a mixed crop and livestock farming system. We then determined sample size for villages (clusters) and households (study units) based on the sentinel site and minimalist approach, (Maxwell et al. (2003). Although they recommend a 20 by 20 cluster 
approach (400 households) as ideal, this study modified this to a 28 villages by 10 households sample so as to fit within available resources. In the second stage, we considered a proportionate stratified sample in selecting the 28 villages so that fewer villages were sampled from the pastoral stratum, which had a lower population spread over an extensive area. Considering that some villages had households quite far apart, transport and access to these households was envisaged a challenge given the limited resources. Professional judgement was thus used to purposively select 21 villages in the agro-pastoral and seven in the pastoral stratum while ensuring a wide spatial and geographical spread over the study area. In the third stage, 10 households were randomly selected from each village using a list of 20 households selected for an earlier survey (Appendix 1). The final sample size was 280 , i.e. 210 households with an agropastoral and 70 households with a pastoral livelihood system. Figure 1 shows the map of the studied area and sampled villages.

\section{Sampling of focus group participants}

From the 28 villages sampled for the household survey, seven villages in the agro-pastoral and five in the pastoral stratum were purposively selected based on the criterion that they were not in close proximity to each other. This was to enable a wide spread of focus groups over the sampled villages. One focus group was put together per village with 12 to 15 participants purposively selected with the help of village (LC I) leaders, based on a principle of gender and age homogeneity as shown in Table 1.

\section{Qualitative data collection}

Focus group discussions (FGDs) were conducted by the lead researcher with a trained research assistant as the note taker. Flipcharts, notebooks and manila flashcards were used to record issues discussed, and in some cases, a digital voice recorder was used. A checklist of CCS generated from data from a previous survey (AfrII 2011) was used to guide discussions; however, participants were requested to mention all strategies they used to ensure they had food for consumption. This study thus opted for the full list of CCS, which according to Maxwell et al. (2008a) has value in identifying the most vulnerable households and is useful as a valid local, context-specific index, as compared to the 'reduced' or core set of behaviours which is more reliable across a variety of contexts.

Each focus group first discussed and agreed that a consumption coping strategy was used within their community and then placed each of them into one of the

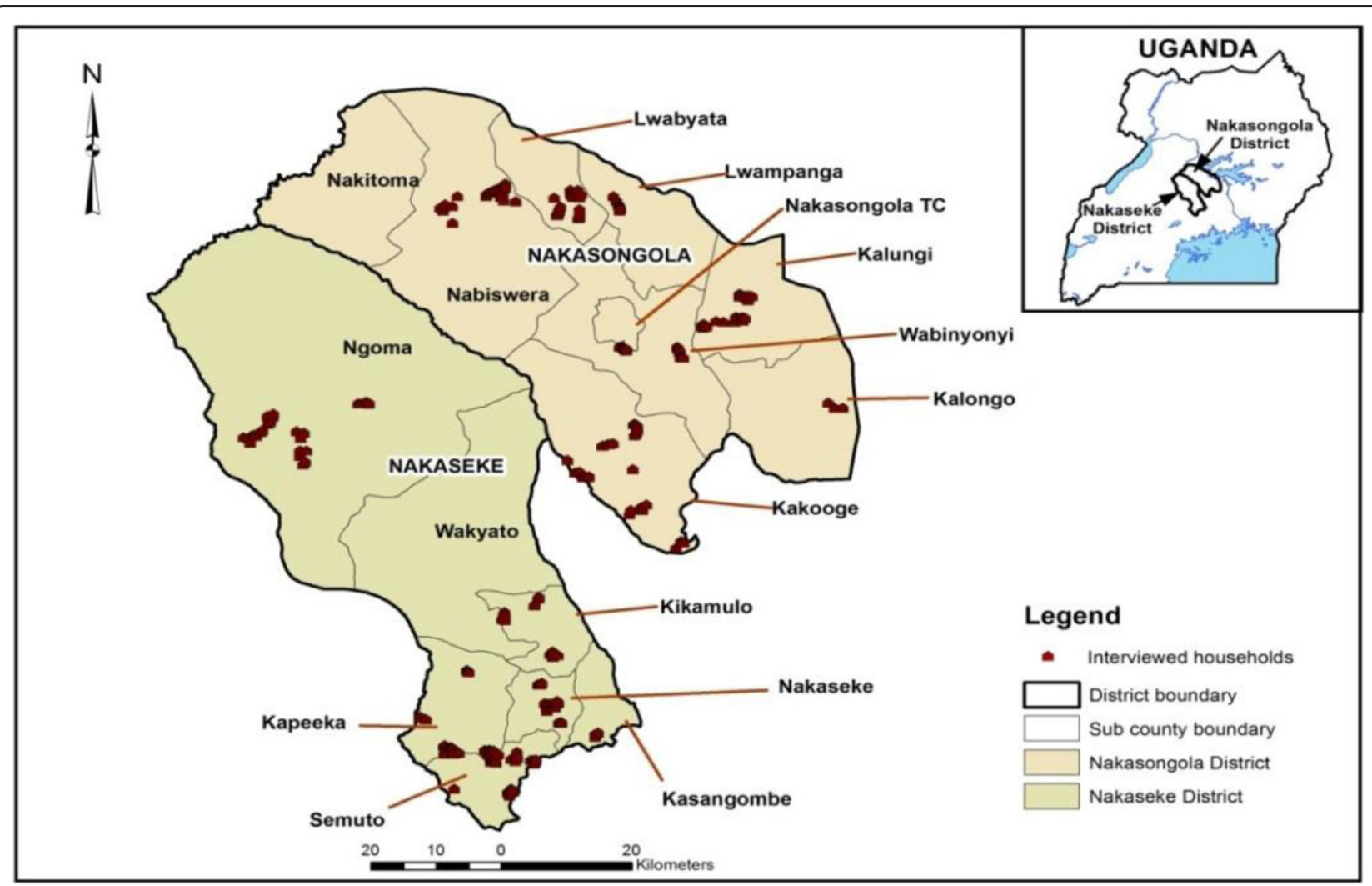

Fig. 1 Map of the study area indicating the location of sampled households (map based on GPS locations taken at every household involved in this study) 
Table 1 Distribution of focus groups

\begin{tabular}{lll}
\hline Participants & $\begin{array}{l}\text { Agro-pastoralist } \\
\text { groups }\end{array}$ & $\begin{array}{l}\text { Pastoralist } \\
\text { groups }\end{array}$ \\
\hline Women 36 to 60 years & 2 & 1 \\
Men 36 to 60 years & 2 & 1 \\
Mixed youth 20 to 35 years & 1 & 2 \\
Mixed older people over & 2 & 1 \\
60 years & 7 & 5 \\
Total & & \\
\hline
\end{tabular}

three 'severity ranks' according to whether extreme, moderate or mild circumstances of food insecurity lead to its use. In order to contextualise and capture community perception better, each focus group was requested to weight these severity ranks in comparison to each other, by distributing 10 stones among them. Table 2 illustrates the consolidated consensus weights allocated by the focus groups to each food insecurity rank by livelihood system.

\section{Quantitative data collection}

A household survey was conducted by two male and two female research assistants who were familiar with the community and language and had been trained to ensure appropriate capture of data. The instrument was an interviewer-administered questionnaire that had been pretested in the study area. This study considered a household to be a person or a closed localised group of people who live together in the same house or compound, share some resources or activities and are catered for as one unit (O'Laughlin 1999). This was explained to every respondent at the start of the inquiry to ensure that the correct data were collected. Each household was geo-referenced, at a level of accuracy of $3 \mathrm{~m}$, using a hand-held Global Positioning System (GPS) with coordinates taken in the WGS 84 geographical coordinate system in decimal degrees. This was to ensure that the household was easily identifiable on subsequent visits.

The head of the household or their spouse was the preferred respondent, but in some cases, another adult member of the household was involved instead. One section of the questionnaire inquired about household member details, livelihood assets and attachment to

Table 2 Perception of comparative weights of the food insecurity ranks by livelihood system

\begin{tabular}{lll}
\hline $\begin{array}{l}\text { Severity of food insecurity } \\
\text { circumstances in household }\end{array}$ & $\begin{array}{ll}\text { Weighting by } \\
\text { agro-pastoralist FGDs }\end{array}$ & $\begin{array}{l}\text { Weighting by } \\
\text { pastoralist FGDs }\end{array}$ \\
\hline Extreme & 6 & 5 \\
Moderate & 3 & 3 \\
Mild & 1 & 2 \\
\hline
\end{tabular}

FGDs focus group discussions social networks. The latter inquired about belonging to community groups, holding community leadership positions or any collective collaboration with fellow community members as listed in Appendix 2. Another section of the questionnaire assessed frequency of use of each of 27 CCS over a recall period of 30 days, based on a standard method (Maxwell et al. 2003). This frequency was assigned a quantitative measure on a weekly basis, i.e. 7 for all the time/every day, 4 for pretty often/three to five times a week, 2 for once in a while/twice a week, 1 for hardly at all/once a week and 0 for never used.

\section{Data management}

The most frequent food insecurity rank and thus corresponding consensus weight assigned by the agro-pastoral and pastoral community FGDs to each of the 27 CCS was noted. These ranks and weights were to reflect, as perceived by the community, the severity of food insecurity circumstances in that agro-pastoral or pastoral household which opted to use selected CCS. For every questionnaire, each consumption coping strategy used was assigned the relevant weight, from those listed in Table 3, based on whether the household was in the pastoral or agro-pastoral stratum. This weight was then multiplied by the quantitative measure of the frequency of use to give the final score for each of the CCS opted for by a household. The sum of the scores of the set of CCS opted for by a household was computed to obtain the CSI as a quantitative indicator of food insecurity.

Based on quartiles of the coping strategy index, four categories were developed to characterise households into the food secure (CSI 0 to 5 ) and then the mildly (CSI 6 to 20), moderately (CSI 21 to 42) and extremely (CSI >42) food insecure. This was to enable a comparative assessment of the households facing different levels of food insecurity and further examine factors that influence the experience of food insecurity within each livelihood system in different seasons.

Data on land holdings were recorded as acres of land accessed for agricultural production. However, to enable management of the wide range of land sizes, it was decided to form five groups based on acreage. Since the majority of households had low land holdings, the first two groups had an interval of 5 while for the last ones it was 50 acres; the groups were thus 0.01 to $5,5.01$ to 10 , 10.01 to 60,60 to 110 and $>110$ acres.

Due to the wide range of livestock species owned by households, in order to make valid comparisons, data on the total number of livestock were computed to a standardised measure - tropical livestock units (TLUs). A tropical livestock unit corresponds to $250 \mathrm{~kg}$ of animal weight; it was computed for each household as the sum of 0.7 per head of cattle, 0.1 per sheep or goat, 0.2 per pig and 0.01 per poultry bird - as recommended by 
Table 3 Focus groups' weighting of consumption coping strategies

\begin{tabular}{|c|c|c|c|}
\hline \multirow[t]{2}{*}{ Code } & \multirow[t]{2}{*}{ Strategy } & \multicolumn{2}{|c|}{ 'Weight' (perceived severity of food insecurity circumstances) } \\
\hline & & Agro-pastoral & Pastoral \\
\hline 1 & Eat less preferred but less expensive foods ${ }^{a}$ & 6 & 5 \\
\hline 2 & Borrow food ${ }^{a}$ & 3 & 2 \\
\hline 3 & Beg for food from a friend or relative & 3 & 5 \\
\hline 4 & Purchase food on credit & 3 & 3 \\
\hline 5 & Gather wild food plants or hunt & 6 & 5 \\
\hline 6 & Harvest immature crops & 1 & 5 \\
\hline 7 & Provide labour in exchange for food & 3 & 3 \\
\hline 8 & Provide labour for income to buy food instead of preparing own fields & 6 & 3 \\
\hline 9 & Consume seed stock held for the next season & 6 & 5 \\
\hline 10 & Slaughter livestock and preserve meat & 1 & 5 \\
\hline 11 & Sell calves to buy food & 1 & 2 \\
\hline 12 & Sell breeding cows to buy food & 6 & 5 \\
\hline 13 & Sell other cattle types to buy food & 1 & 2 \\
\hline 14 & Sell other livestock to buy food & 1 & 2 \\
\hline 15 & Sell assets to buy food & 6 & 5 \\
\hline 16 & Send household members to eat elsewhere & 6 & 5 \\
\hline 17 & Send household members to beg/fend for themselves & 6 & 5 \\
\hline 18 & Limit portion size at meal times $^{a}$ & 3 & 3 \\
\hline 19 & Restrict consumption of adults in order for small children to eat ${ }^{\mathrm{a}}$ & 3 & 3 \\
\hline 20 & Feed working members of $\mathrm{HH}$ at the expense of non-working members & 1 & 2 \\
\hline 21 & Ration the money available and buy pre-cooked food & 3 & 3 \\
\hline 22 & Reduce the number of meals eaten in a day ${ }^{a}$ & 3 & 3 \\
\hline 23 & Skip entire days without eating & 6 & 5 \\
\hline 24 & Barter (exchange an item for food) & 6 & 5 \\
\hline 25 & Send children out to labour and earn to buy food & 6 & 5 \\
\hline 26 & Send girl children for early marriage & 6 & 5 \\
\hline 27 & Reduce the number of people in the household, e.g. send to a relative & 6 & 5 \\
\hline
\end{tabular}

The maximum possible weight was 6 for agro-pastoralists and 5 for pastoralists; the minimum weight was 1 and 2, respectively (details in Table 2). ${ }^{\mathrm{a} C o r e}$ behaviours broadly comparable across contexts

Jahnke et al., cited in Benson and Mugarura (2010) Based on the fact that several households had low livestock holdings, the TLU data were then divided into five groups: the first two had an interval of 1.5 and the last ones 10, i.e. 0.01 to $1.5,1.51$ to $3,3.01$ to $13,13.01$ to $23,>23$.

Data on the social networks were compiled as binomials, i.e. either belonging to one or more social networks (1) or not belonging to any (0). For the two rounds of quantitative data collection per household, there were 250 well-completed questionnaires meaning that $89 \%$ of the targeted households were followed up consistently.

\section{Statistical analysis}

Data were analysed using Excel, $\mathrm{R}$ statistical and Stata 12 software, and differences at $p<0.05$ were considered significant for all tests. The $t$-test was used to check the difference between means of CSI data for the two livelihood groups. The $\chi^{2}$ test was used to check the association of grouped CSI data (food insecurity categories) with household head's gender, education level, age, ethnicity and household parameters including household size and livelihood system (determinants). ANOVA was then used to check variations in grouped CSI for those parameters that were significant. Multinomial logistic regression was used to check dependence of the four CSI groups on livelihood system and livelihood assets which included the five land holding categories: 0.01 to $5(n=116), 5.01$ to $10(n=54)$, 10.01 to $60(n=29), 60$ to $110(n=5)$ and $>110$ acres $(n=19)$, tropical livestock unit categories: 0.01 to 1.5 $(n=83), 1.51$ to $3(n=49), 3.01$ to $13(n=55), 13.01$ to $23(n=18),>23(n=23)$ and a binomial of either belonging to a social network or not. 


\section{Results}

\section{Community perceptions of food insecurity}

Some perceptions of what constitutes food security and insecurity were associated only with pastoralism or agropastoralism, and some were common to both. Agropastoralists described the food secure as those who could afford to sell off some food items especially cassava, sweet potatoes or groundnuts and were never seen carrying polythene bags of such food from the market. In contrast, pastoralists described the food secure as those who often bought food. They stressed that to them market dependency was a norm; the issue was whether one could afford the required food items or not. However, with respect to consumption, both agro-pastoralists and pastoralists described the food secure as those who ate preferred foods like matooke (green banana), rice and sweet potatoes, and the food insecure as those who only consumed millet or maize flour as solid food or porridge or even sometimes went to bed hungry at night. Unique to the agro-pastoralists was that the food secure were those who had at least 2 to 3 acres of cassava and granaries of stored food while the food insecure did not store food; pastoralists did not mention cultivation-related issues.

The perceptions of pastoral and agro-pastoral communities about severity of food insecurity circumstances in a household by the time they used a consumption coping strategy are reflected by the weighting shown in Table 3.

The perception by the agro-pastoral community was that those CCS ranked in the extreme category (weight $=6$ ) were associated with food insecurity circumstances twice as severe as those in the moderate category and six times those in the mild category. A female participant in an agropastoralist mixed youth FGD in Kalyakoti village, Wampiti Parish, Nakasongola District (July 2012), stressed this by saying: '...the rank of extreme food insecurity reflects a very bad situation which doubles the state of moderate food insecurity'. In contrast, the pastoral communities did not perceive much difference between the moderate (weight $=3$ ) and mild ranks (weight $=2$ ), but their view was that the latter should not be weighted too low. These perceptions suggest that the difference in severity may have been greater between the moderate and extremely food insecure than between the mild and moderate categories.

Different reasons were given by pastoral and agropastoral communities for allocating a 'weight' to a consumption coping strategy, and some of those where the two communities gave the most contrasting reasons are as detailed in Table 4.

Some CCS were used in extreme circumstances of food insecurity by both pastoral and agro-pastoral informants. For example, about 'gathering wild food crops or hunting, a participant in a women-only agro-pastoralist group in Kyampisi village, Kisoga Parish, Nakaseke District said: 'This would definitely only occur under extreme circumstances; it is not good to gather wild food. In fact there is a saying that one who gathers from the wild can never satisfy hunger'. A participant in a menonly pastoralist group in Kamusenene B Village, Buwana Parish, Nakaseke District said: 'Those would be extreme circumstances of food insecurity; we pastoralists do not gather wild food'.

\section{Relative state of and factors influencing household food insecurity}

At the start of the dry season, the difference between mean CSI of pastoral and agro-pastoral households was not significant $(t=-0.1673, d f=122.364, p$ value $=0.867)$. However, it was highly significant $(t=-2.894, d f=87.947$, $p=0.005)$ at the start of the rains, and Fig. 2 illustrates that pastoralists were more food insecure than agro-pastoralists.

The household food insecurity categories were significantly associated with season $\left(\chi^{2}=28.1, d f=3, p<0.001\right)$. At the start of the dry season, the mean CSI was $29.4 \pm$ 2.59 (95\% CI of 24.3 to 34.5), and the largest proportion of households (33.6\%) was in the food secure category. At the start of the rains, the mean CSI was higher at $33.1 \pm 2.30$ (95\% CI of 28.6 to 37.6), and only $14 \%$ of the households were food secure. As illustrated in Table 5, between the start of the dry and rainy seasons, there was also an increase in those moderately food insecure.

The seasonal pattern of food insecurity categories was significantly associated with livelihood system. Between the start of the dry season and the start of the rains, the proportion of extremely food insecure households increased by 22.7 percentage points for the pastoralists but only by 3.1 percentage points for agro-pastoralists $\left(\chi^{2}=22.40\right.$, $d f=3, p<0.001)$. The simultaneous decrease in the proportion of households that were food secure was 22.6 and 18.7 percentage points, respectively $\left(\chi^{2}=45.83\right.$, $d f=3, p<0.001)$. Figure 3 shows how the proportions of households varied between food insecurity categories.

The CSI was neither associated with household size nor household head's level of education or age, but gender was almost significant $(p=0.07)$ - female-headed agro-pastoral households trended toward having a higher CSI. The variation of CSI with household head's ethnicity was highly significant at the start of the dry season $(F=3.263, d f=7, p=0.002)$ and close to significant at the start of the rains $(F=1.905, d f=7, p=0.07)$. Household heads were from a range of ethnic groups including Baruuli $(n=106)$, Baganda $(n=72)$, Banyankore $(n=31)$, Migrants $(n=24)$, Banyoro $(n=7)$, Northern tribes $(n=4)$, Eastern tribes $(n=4)$ and Bakiga $(n=2)$. Belonging to some ethnic groups, e.g. the Northern ethnic groups, seemed to be linked with food insecurity while others, e.g. the Eastern ethnic group, were linked 
Table 4 Differences in perceptions of CCS among pastoral and agro-pastoral communities

\begin{tabular}{ll}
\hline Coping strategy & Agro-pastoral community \\
\hline $\begin{array}{l}\text { Beg for food from a friend } \\
\text { or relative }\end{array}$ & Ranked moderate - 3 \\
& $\begin{array}{l}\text { Reason: Households do this when food crops are available } \\
\text { in the garden but not ready to harvest - when there was a } \\
\text { relative who had food and one could beg and get some, } \\
\text { at least the situation was not too bad }\end{array}$
\end{tabular}

Pastoral community

Ranked extreme - 5

Reason: Pastoralists do not grow food crops; thus, it is almost unheard of for one to beg for food from another. When this happens, the situation must be extremely bad. A participant in a men-only group in Kamusenene B, Buwana Parish, Nakaseke District stressed this, saying: 'We don't do that because we don't grow crops - so what will you get when you beg from a friend? During drought we all do not have milk, so one can only borrow from a shop not from a friend'

Provide labour for income Ranked extreme - 6

Ranked moderate - 3

to buy food instead of

preparing own fields

Harvest immature crops

Slaughter livestock and preserve meat
Reason: Own food crop growing is a priority for most households, so one which opted to labour elsewhere had to be in a desperate position of no food or very limited space to grow crops. A male participant (July 2012) in Kalyakoti mixed youth FGD, Wampiti Parish, Nakasongola District, emphasised thus: This is done in extreme conditions because, normally when you labour for five days, the income you get can purchase food enough for only 2 days'

Ranked mild - 1

Reason: Best expressed by a participant in a women-only group (July 2012) in Matabi Village Kamuli Musaale Parish as: '..at least that household even has food crops but may only have been caught up in a temporary situation of immediate need of food'

Ranked mild - 1

Reason: Best stressed by a male participant of a mixed youth group (July 2012) in Kalyakoti village, Wampiti

Parish, Nakasongola District, who argued thus: 'If one has an animal to slaughter and can even decide to keep some of the meat it means they have something'.
Reason: Many households do not own crop fields and after tending their animals may have time to provide labour for extra income to buy food, but the situation is not really desperate. A participant (July 2012) in a men-only group in Kamusenene B, Nakaseke District explained: 'Someone may do this because he has some immediate needs not yet met, but not that the circumstances are very bad'

Ranked extreme - 5

Reason: Emphasised by a participant in a men-only group (July 2012) in Kamusenene B village, Nakaseke District as: '..livestock keepers are not cultivators, those who decide to grow food only harvest mature crops which are delicious enough to eat. If one harvests immature crops then they can't afford to buy food so are facing extreme circumstances of lack of food'

Ranked extreme - 5

Reason: Pastoral households have small stock especially goats which could be slaughtered whenever needed so one who preserved meat for the future had to be in an extremely desperate situation. One participant in a men-only group (July 2012) in Kamusenene B village, Nakaseke District said: We do not have the practice of storing dried meat. We can slaughter a sheep or goat at any time - not only during food insecure times'. to food security. Table 6 gives details of CSI by ethnic group, at the start of the first dry season, indicating those that were more or less than the average for that season.

Table 7 summarises data on landholding and gives details of the different livestock species making up the TLUs.

At the start of the dry season, a decline in CSI (increased food security) as landholdings increase, a relationship that was stronger among agro-pastoralists, is demonstrated by the plots in Fig. 4.

Analysis of categorised data revealed that at the start of the dry season, the CSI score category to which a household belonged was dependant on the landholdings $\left(\chi^{2}=9.11, d f=3, p=0.03\right.$, pseudo $\left.R^{2}=0.014\right)$. The higher the landholdings, the higher the probability of being more food secure, a situation also illustrated in Table 8 - for the majority of households, the proportion of the food secure generally increased as landholdings increased.

TLUs owned by a household were associated with CSI at the start of the first rains $\left(\chi^{2}=25.67, d f=12, p<0.05\right)$, but not at the start of the dry season. At the start of the rains (Fig. 5), pastoralists had slightly higher levels of food insecurity overall but showed no CSI trend by TLUs; however, agro-pastoral households' CSI decreased (increased food security) as the number of TLUs increased.

Categorised data showed that at the start of the rains, the CSI score category to which a household belonged was dependant on the TLU $\left(\chi^{2}=8.62, d f=3, p=0.03\right.$, pseudo $\left.R^{2}=0.013\right)$. The higher the TLU, the higher the probability of a household belonging to a more food 


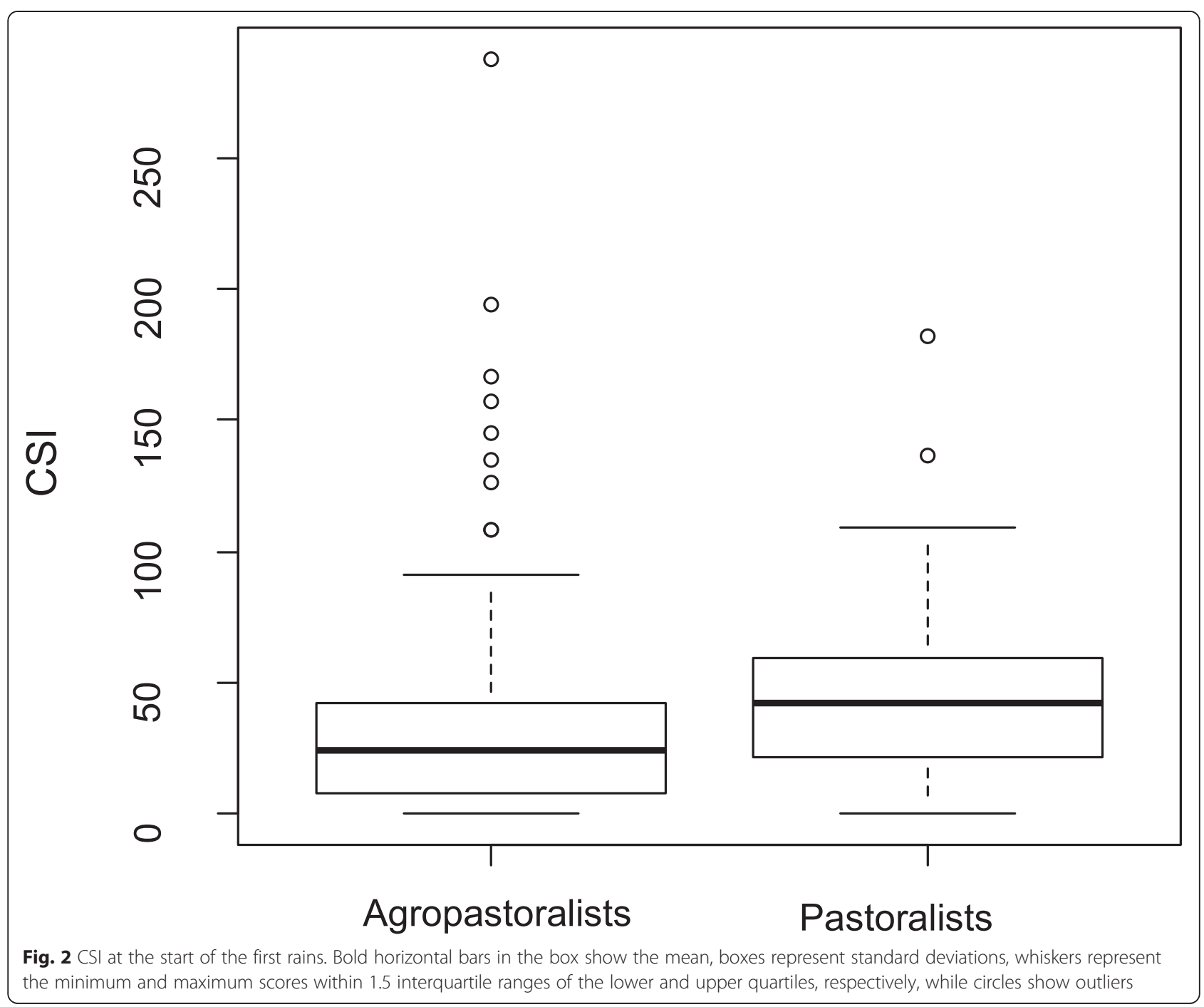

secure category. However, Table 9 shows that the proportion of food secure households decreased as TLU group became larger.

Social networks with which households were involved included those that allowed them access to product marketing services, financial saving and credit facilities, government agricultural extension services and inputs, skills training, developing sports talent, medical care, community leadership responsibilities, income-generating opportunities and social support from fellow community members (see
Appendix 2 for the types of social networks qualifying). Overall, $50.8 \%$ of the households belonged to a social network with pastoralists at a higher level (67.9\%) than agropastoralists (46.2\%).

At the start of the dry season, the household CSI did not show any association with a household head or adult member belonging to a social network, and the association between CSI groups and belonging to a social network was not significant. However, at the start of the rains, although the disaggregated CSI did not show any association with

Table 5 Household food insecurity status by season

\begin{tabular}{|c|c|c|c|c|c|}
\hline & $\begin{array}{l}\text { Food secure (CSI } 0 \\
\text { to } 5)\end{array}$ & $\begin{array}{l}\text { Mild food insecurity (CSI } 6 \\
\text { to 20) }\end{array}$ & $\begin{array}{l}\text { Moderate food insecurity (CSI } \\
21 \text { to } 42 \text { ) }\end{array}$ & $\begin{array}{l}\text { Extreme food insecurity } \\
(\mathrm{CSI}>42)\end{array}$ & $\begin{array}{l}\text { Total } \\
(\%)\end{array}$ \\
\hline $\begin{array}{l}\text { Start of dry season } 2012(n \\
=250)\end{array}$ & $33.6 \%$ & $22.8 \%$ & $23.2 \%$ & $20.4 \%$ & 100 \\
\hline $\begin{array}{l}\text { Start of rainy season } 2013(n \\
=250)\end{array}$ & $14 \%$ & $29.6 \%$ & $33.6 \%$ & $22.8 \%$ & 100 \\
\hline
\end{tabular}




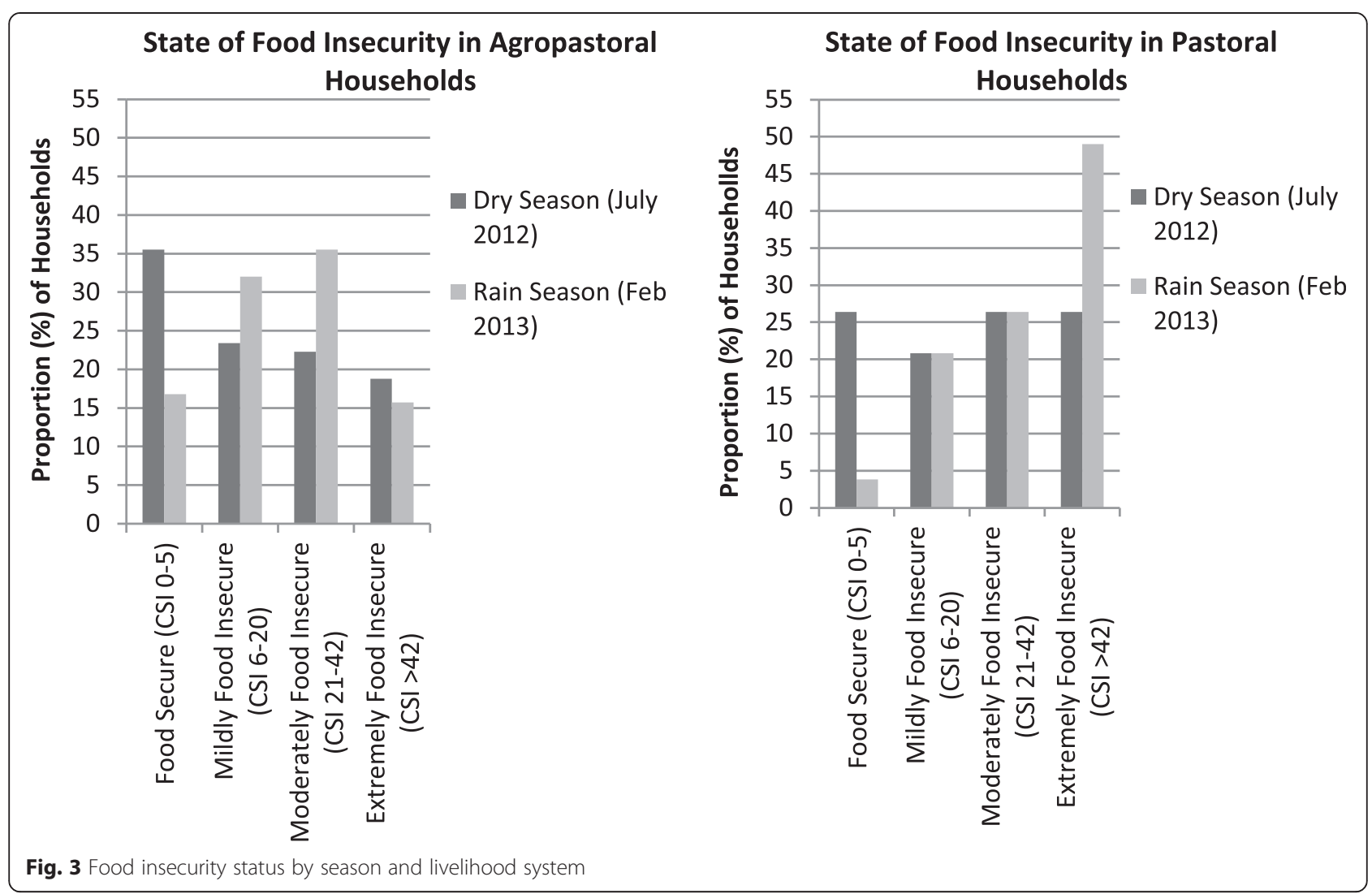

belonging to a social network, when categorised, CSI groups were highly associated with belonging to a social network $\left(\chi^{2}=16.82, d f=3, p<0.001\right)$.

The multinomial logistic regression model used to check for variance of relative food insecurity status with livelihood assets showed that in the rainy season, food insecurity status was associated with a combination of livelihood system, land holdings, TLUs and belonging to a social network $\left(\chi^{2}=52.56, d f=36, p=0.04\right.$, pseudo $R^{2}=0.0785$ ).

At the start of the dry season, up to $8.7 \%$ of the variance in food insecurity status among agro-pastoral households was linked to the land holdings and TLUs in combination $\left(\chi^{2}=46.99, d f=30, p=0.02\right.$, pseudo $\left.R^{2}=0.087\right)$. The inclusion of belonging to a social network to the land holdings and TLUs in combination then explained $10 \%$ of the variance in agro-pastoralists' food insecurity status $\left(\chi^{2}=53.98, d f=33, p=0.012\right.$, pseudo $\left.R^{2}=0.1002\right)$. At the start of the rainy season, $9.2 \%$ of the variance in food insecurity status depended on the land holdings and TLUs in combination $\left(\chi^{2}=48.29, d f=30, p=0.02\right.$, pseudo $R^{2}=0.092$ ), and belonging to a social network added only $0.2 \%$ to the variance $\left(\chi^{2}=49.39, d f=33\right.$, $p=0.033$, pseudo $R^{2}=0.0941$ ).

Little variance was explained by these measured factors among the pastoralists in either season.

\section{Discussion}

In exploring the utility of a CSI to describe food insecurity, relative differences were revealed among households within and between the pastoral and agro-pastoral livelihood systems. Compared to a near equal mean CSI for

Table 6 CSI score at the start of the dry season by household head's ethnic group

\begin{tabular}{|c|c|c|c|}
\hline \multicolumn{2}{|c|}{ Ethnic groups with CSI >29.4 (less food secure than seasonal mean) } & \multicolumn{2}{|c|}{ Ethnic groups with CSI $<29.4$ (more food secure than seasonal mean) } \\
\hline Agro-pastoralists & Pastoralists & Agro-pastoralists & Pastoralists \\
\hline Northern $^{a}(69 \pm 19.8)$ & $\mathrm{N} / \mathrm{A}$ & Mukiga $(24 \pm 27.9)$ & N/A \\
\hline Munyoro $(66 \pm 17.6)$ & & & Munyoro (16 \pm 27.9$)$ \\
\hline Munyankore $(54 \pm 22.8)$ & Munyankore (35 \pm 7.5$)$ & Eastern $^{c}(16 \pm 22.8)$ & Eastern $(24 \pm 39.5)$ \\
\hline Migrants $^{b}(49 \pm 9.6)$ & Migrants (48 \pm 16.1$)$ & Muganda $(17 \pm 4.9)$ & Muganda $(11 \pm 16.1)$ \\
\hline Muruuli $(30 \pm 4.0)$ & & & Muruuli $(20 \pm 12.5)$ \\
\hline
\end{tabular}

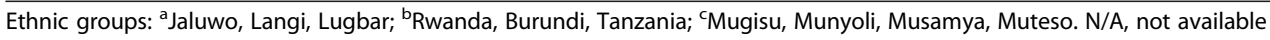


Table 7 Households' livestock and land holdings

\begin{tabular}{lllllcr}
\hline & Pigs & Chicken & Sheep and goats & Cattle & Tropical livestock units & Land holding (acres) \\
\hline Mean & 1.40 & 7.60 & 3.70 & 9.76 & 7.56 & 33.98 \\
Standard deviation & 2.18 & 9.09 & 6.99 & 23.16 & 16.62 & 102.98 \\
Maximum & 14 & 80 & 52 & 250 & 178.1 & 700.00 \\
\hline
\end{tabular}

households from both livelihood systems at the start of the dry season, pastoralists had a much higher mean CSI (greater food insecurity) than agro-pastoralists at the start of the rains. This was possibly because the latter was a season when food amounts had dwindled so pastoralists had to use coping strategies more frequently and employ those with a higher weighting, reflecting circumstances of greater household food insecurity. Agropastoralists coped better at the start of the rains since their food stocks may not have run out completely so they exhibited a lower CSI and thus less evident food insecurity. The fact that using the CSI actually revealed differences among livelihood groups suggests that, as recommended by Renzaho and Mellor (2009), focustested CCS, like those considered in this study, were suitable, relevant indicators of food insecurity. Capturing the differences in the 'weight' of CCS as perceived by pastoral and agro-pastoral communities allowed a fair comparison of the household food security status in the two livelihood systems. Despite some similarities, some perceptions of the food secure and food insecure were unique to each livelihood group and thus reflected what Adger (2006) described as 'vulnerability as experienced by the vulnerable'.

Pastoralist livelihood system and the start of the rains were both factors increasing the experience of food insecurity. Larger proportions of pastoral than agro-pastoral households moved out of the food secure and into the extreme food insecurity category between the start of the dry season and the rains, which was a manifestation of seasonal vulnerability to food insecurity. The movement out of food security into food insecurity from the dry to subsequent rainy season was expected, largely because the major harvest took place just before the dry season, but it is worth noting that for agro-pastoralists, a proportionately small additional number of households

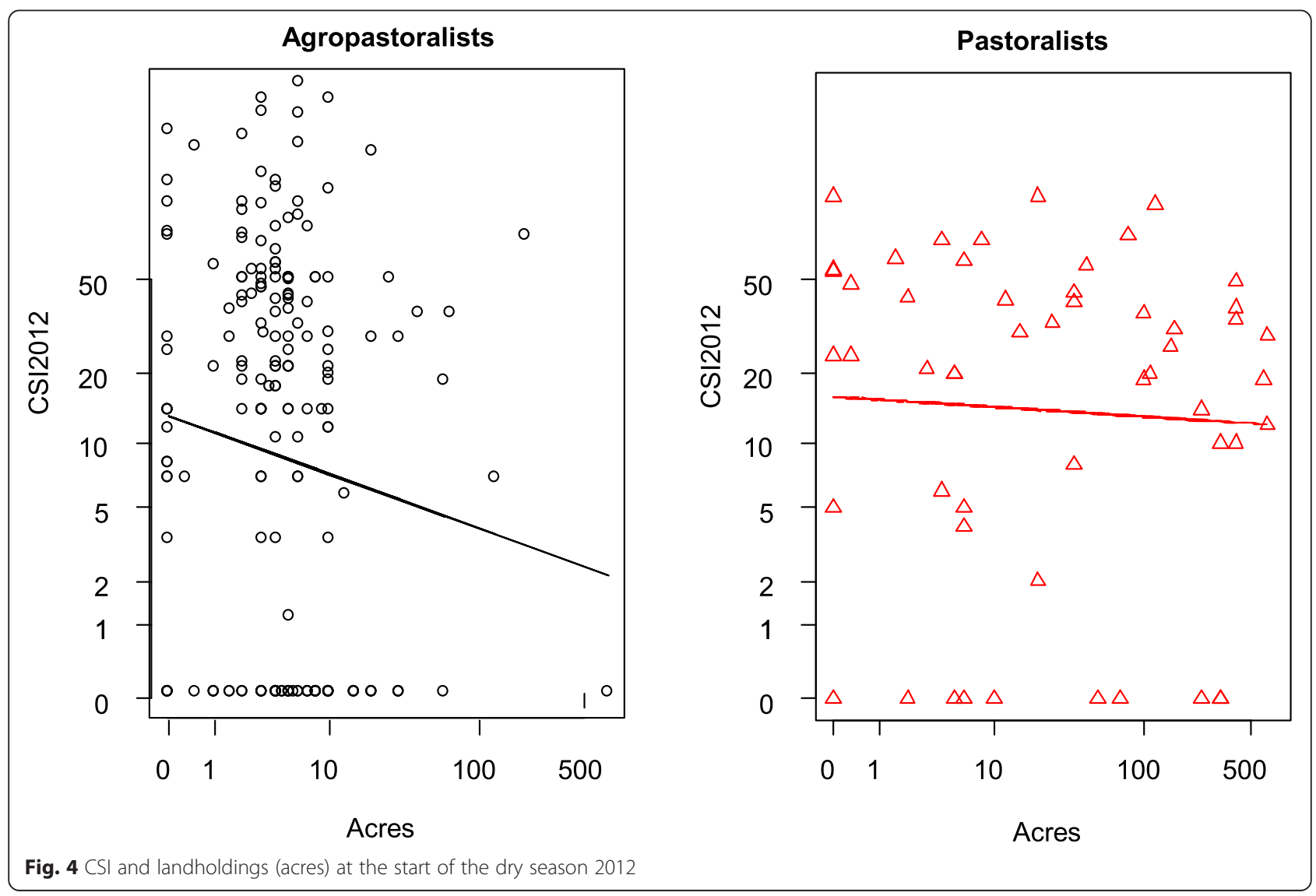


Table 8 Proportion of households by food insecurity and land holding at the start of the dry season 2012

\begin{tabular}{|c|c|c|c|c|c|}
\hline Land holding (acres) & $\begin{array}{l}\text { Food secure: CSI } 0 \text { to } 5 \\
(n=76)\end{array}$ & $\begin{array}{l}\text { Mild food insecurity: } \\
\text { CSI } 6 \text { to } 20(n=49)\end{array}$ & $\begin{array}{l}\text { Moderate food insecurity: } \\
\text { CSI } 21 \text { to } 42(n=55)\end{array}$ & $\begin{array}{l}\text { Extreme food insecurity: } \\
\text { CSI }>42(n=43)\end{array}$ & Total (\%) \\
\hline 0.01 to $5(n=116)$ & 26.7 & 24.1 & 27.6 & 21.6 & 100 \\
\hline 5.01 to $10(n=54)$ & 46.3 & 20.4 & 14.8 & 18.5 & 100 \\
\hline 10.01 to $60(n=29)$ & 48.3 & 6.9 & 27.6 & 17.2 & 100 \\
\hline 60 to $110(n=5)$ & 20.0 & 40.0 & 40.0 & 0.0 & 100 \\
\hline$>110(n=19)$ & 26.3 & 31.6 & 26.3 & 15.8 & 100 \\
\hline
\end{tabular}

became extremely food insecure compared to those who came out of the food secure category. This calls for further investigation but could indicate that unlike pastoralists who were either food secure or extremely food insecure, agro-pastoral households went into a lesser state of food insecurity (e.g. moderate) which fact was also reflected during focus group discussions. The findings of an association between ethnicity of the household head and seasonal variation in food insecurity and that, notably, both pastoral and agro-pastoral migrant groups fell more often into the extremely food insecure category stress the importance of taking into account the social and cultural contexts in which coping strategies occur. When such contexts are not considered, coping strategies may be misleading surrogate measurements of food insecurity (Renzaho and Mellor 2009).
Only at the start of the dry season did food insecurity decrease with increasing land access; particularly for agro-pastoralists, this could be attributed to a time of plenty from cultivation activities and less frequent use of livestock as coping strategies. At the start of the rains being planting time and a period of food crop scarcity the higher the livestock wealth as expressed in TLUs, the increased likelihood of a household being more food secure. In apparent contradiction, the proportion of households in the food secure category decreased as TLUs increased, and the group with the largest number of TLUs had a large proportion of households in a state of extreme food insecurity. It is possible that, though our analysis could not confirm this, households with higher TLUs tended to have attracted more household members (e.g. peripheral kin attaching themselves to the

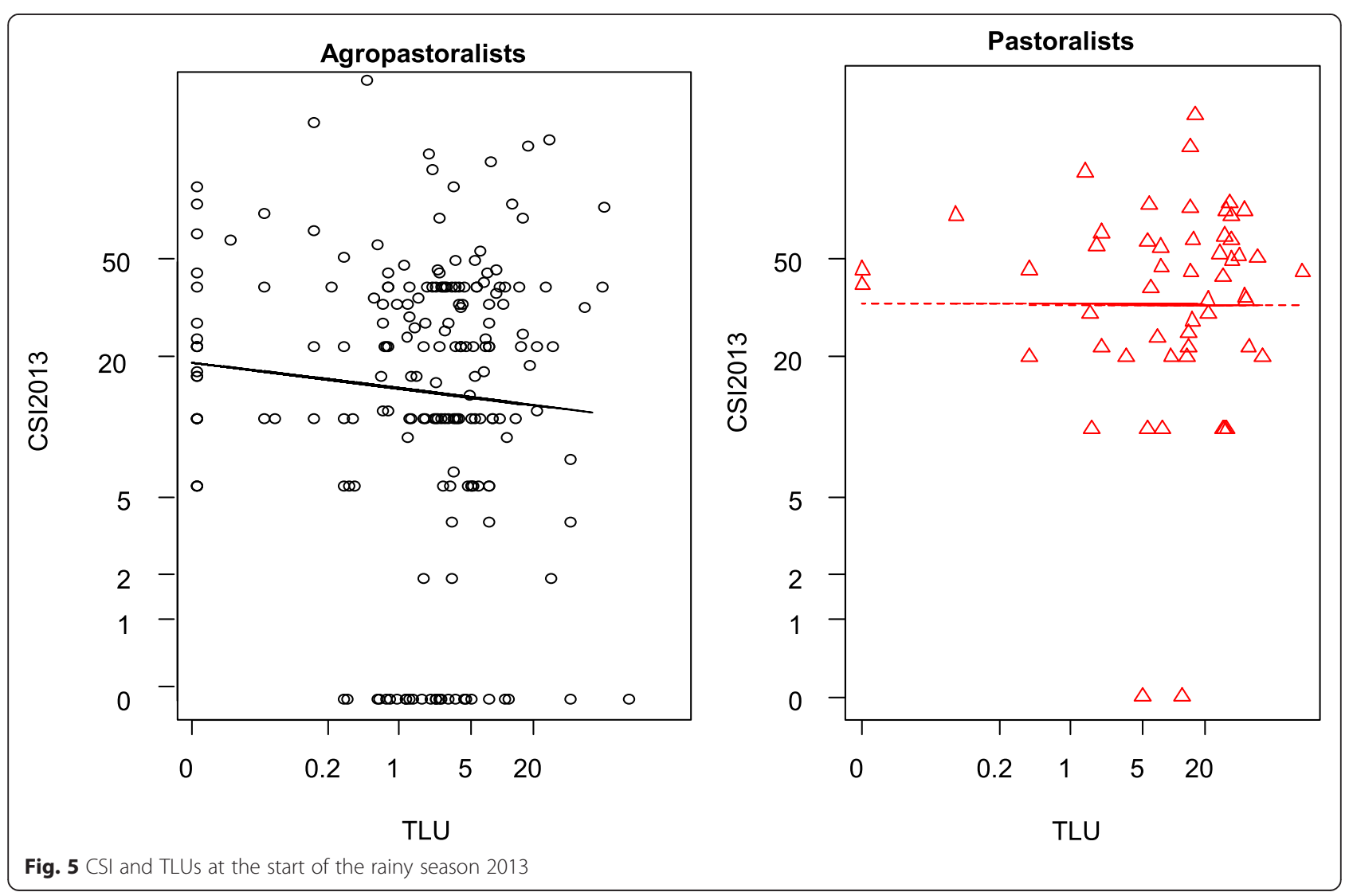


Table 9 Proportion of households by food insecurity and TLUs at the start of the rainy season 2013

\begin{tabular}{|c|c|c|c|c|c|}
\hline TLUS & $\begin{array}{l}\text { Food secure: CSI } 0 \text { to } 5 \\
(n=35)\end{array}$ & $\begin{array}{l}\text { Mild food insecurity: } \\
\text { CSI } 6 \text { to } 20(n=74)\end{array}$ & $\begin{array}{l}\text { Moderate food insecurity: } \\
\text { CSI } 21 \text { to } 42(n=84)\end{array}$ & $\begin{array}{l}\text { Extreme food insecurity: } \\
\mathrm{CSI}>42(n=57)\end{array}$ & Total (\%) \\
\hline 0.01 to $1.5(n=83)$ & 20.5 & 27.7 & 30.1 & 21.7 & 100.0 \\
\hline 1.51 to $3(n=49)$ & 16.3 & 34.7 & 42.9 & 6.1 & 100.0 \\
\hline 3.01 to $13(n=55)$ & 10.9 & 32.7 & 32.7 & 23.6 & 100.0 \\
\hline 13.01 to $23(n=18)$ & 16.7 & 11.1 & 38.9 & 33.3 & 100.0 \\
\hline$>23(n=23)$ & 4.3 & 17.4 & 26.1 & 52.2 & 100.0 \\
\hline
\end{tabular}

TLUs tropical livestock units

household), though with the wide range of livestock unit holdings reported, any such effect would be slight. It is also possible that in the context of the CSI, such households had the livestock numbers that enabled them to cope either by the use of CCS reflecting greater food insecurity, e.g. sale of high-value breeding stock, or more frequent use of those reflecting less food insecurity like sale of calves or small livestock, or both. A study in Kenya found somewhat related results in that CSI was positively but weakly correlated with livestock income (Maxwell et al. 2003); however, that study did not take seasonal effects into consideration. The current study showed that pastoralists probably attached more importance to belonging to social networks than agro-pastoralists (68\% compared to $46 \%$ respectively attached to social networks). The significant association of food insecurity categories with belonging to a social network only at the start of the rains could be an indication that people in a precarious situation (food-scarce times) would make greater efforts to belong, as a survival strategy, so that social networks provide support mechanisms to help households in utilising CCS. For example, agro-pastoralists belonging to a neighbourhood support group may find it easier to ask for food from a friend, provide labour in exchange for food or borrow food, while pastoralists belonging to a commodity marketing group may enhance their ability to purchase food on credit or sell livestock at better prices to enable them to purchase larger amounts of food.

This assessment of the factors influencing household food insecurity revealed that depending on season, the combination of livelihood system, land holdings, TLUs and belonging to a social network explained only $7.9 \%$ of the variance in household food insecurity. Therefore, most of the factors that make up the variance in food insecurity are unexplained by the variables considered in this study. Such factors could include different sources of household income, which showed negative correlation with CSI according to a study of the Embo community in South Africa by Mjonono et al. (2009). Nevertheless, the results in the current study conform with the notion that vulnerability is related to the asset portfolio, livelihood activities and the context surrounding the people (Løvendal and Knowles 2005). While pastoralists' food insecurity status did not show significant dependence on the combined factors, the fact that among agro-pastoral households only $8.7 \%$ to $9.2 \%$ of the variance in food insecurity status depended on the land holdings and TLUs in combination to some extent conforms with the notion that gardens do not provide sufficient food to impact positively on food security status (Mjonono et al. 2009). However, the results of the current study could also be a demonstration of the difficulties in modelling or predicting vulnerability of subsistence or smallholder farmers as noted by Morton (2007). The characteristics of these systems, particularly their complexity and integration of agricultural and non-agricultural livelihood strategies, as well as their vulnerability to a range of climate-related and other stressors such as poor market access contribute to these difficulties (Morton 2007). Nevertheless, assessing the livelihood assets is important so as to identify which categories of food insecure households can be targeted with what approach, given the Renzaho and Mellor (2009) notion that asset creation should be part of food security initiatives concerned with putting in place structures and systems that sustain a household's ability to withstand sudden shocks that threaten their access to food.

This study employed the CSI as an indicator of shortterm food security status, providing baseline information from the surveys in two different seasons. Subsequent surveys carried out at the same time of the year could track impact of development projects directed at household food security, as was recommended by Maxwell et al. (2003). The findings of this study emphasise what Ahamad and Khondker (2010) noted that seasonal food insecurity is often transitory as a result of seasonal fluctuations of coping strategies, which may be an outcome of socioeconomic circumstances and variation in climatic factors. Limitations in the current study include the purposive selection of sample villages - increasing the likelihood of bias, unequal sample sizes for the two livelihood groups and the small sub-sample sizes for the TLUs and the land holdings. Total land holdings were considered without separating that not used for agriculture, which could be a source of variability not included in the models. The possible difference in qualitative 
meanings of the same coping strategy for poorer and wealthier households was not explored; for example, it is likely that selling animals means something different and is practised in different circumstances, by poorer and wealthier pastoral households. Finally, data on livelihood diversification by households were limited.

\section{Conclusion}

There are key differences between the food security profiles of pastoralists and agro-pastoralists, as evidenced by differences in the coping strategies they adopt and the intensity with which they adopt them. Climatic season and livelihood system were quite important in relation to the state of food insecurity. Even as pastoralists demonstrated higher movement out of food security to food insecurity between seasons, they also manifested a higher percentage of extremely food insecure households than agro-pastoralists. In the dry season, the only factor that was highly significant in increasing the experience of food insecurity was low landholdings, but gender was nearly significant, particularly female headedness in agro-pastoral households. In the rainy season, the factors that were highly significant in increasing the experience of food insecurity were pastoral livelihood, non-involvement in social networks and high livestock holdings. What are commonly considered major livelihood assets like TLUs and land holdings explained very little of the variance in food insecurity in either season in this sample. Further research is needed to find out why this was the case, including in-depth analysis of linkages between food insecurity in this area of Uganda and extremes in climatic seasons as well as household parameters including gender, ethnicity, being a migrant and livelihood diversification. Interventions seeking to stabilise consumption should incorporate climatic considerations as well as differences in food security between pastoral and agropastoral livelihood groups.

\section{Appendices \\ Appendix 1 \\ Sampling for the baseline survey}

A baseline survey was done in Nakasongola and Nakaseke districts in 2011 by a Ugandan-based organisation, Africa Innovations Institute (AfrII), as part of an IDRC-funded project on adaptation to climate change. The two districts were stratified into three farming systems, i.e. pastoralmajority areas, areas of extensive grazing by mixed crop-livestock-producers and crop farming areas. Using the registers at the parish local council chairpersons' offices as the sampling frame, 30 villages were randomly selected from each strata per district $(2 \times 30)$ to give 60 villages per stratum and from the three strata $(60 \times 3)$ a total of 180 villages in the study area. Then, using registers at village local council chairmen's offices, 20 households were selected in each of the sampled villages $(20 \times 180)$, making a total sample of 3,600 households. Out of those, the present study was based on a sample frame of 2,400 households only from the pastoral-majority and crop-livestock areas, i.e. 2 strata $\times 60$ villages $\times 20$ households.

\section{Appendix 2 \\ 'Social networks' of household members included in this study}

1. Income generation support groups

2. Women's Development groups

3. Money sharing 'circles'

4. National Agricultural Advisory Services (NAADS) farmers' groups

5. Farmers' groups

6. Religious groups

7. Religious charity groups

8. Adult learning support groups

9. Village leadership

10. Political group leadership

11. Church leadership

12. Parents-Teachers Associations leadership

13. Drama groups

14. Savings and credit cooperatives

15. Neighbourhood support groups

16. Commodity marketing groups

17. Health support groups

18. Youth development groups

19. Microfinance institution groups

\section{Competing interests}

The field work for this study was supported by the Adaptation to Climate Change Project of the Africa Innovation Institute, Uganda, which was funded by IDRC. The first author is a PhD student at Makerere University and partially funded by small grants from the Next Generation of African Academics

Project of Makerere University which is supported by Carnegie Corporation of New York. She was funded by the UK government as a Commonwealth Split-site PhD Scholar at the Natural Resources Institute, University of Greenwich. The other authors declare that they have no competing interests.

\section{Authors' contributions}

MM conceived and designed the study; collected, analysed and interpreted the data; and drafted the manuscript. RA supervised the data collection process and gave comments for improvement of the manuscript. TG made a critical review of the manuscript drafts and provided input for its

improvement. JM reviewed several drafts; commented on the pastoral context, analyses and argument; and approved the final manuscript. All the authors read and made comments that improved the final manuscript.

\section{Authors' information}

$M M$ is a veterinarian, an assistant lecturer and PhD research student in the College of Veterinary Medicine at Makerere University, Uganda, and a Split-site commonwealth scholar at the University of Greenwich, UK. RA is a Professor of Veterinary Parasitology at Makerere University, Uganda, and a lead researcher with Africa Innovations Institute, Uganda. TG is a Professor of Nutrition in Dept. of Nutrition, Hanyang University, South Korea, and former Visiting Professor at Natural Resources Institute, University of Greenwich, UK. JM is a Professor of Development Anthropology at the Natural Resources Institute, University of Greenwich, UK. 


\section{Author details}

'Dept of Biosecurity, Ecosystem and Veterinary Public Health, College of Veterinary Medicine, Animal Resources and Biosecurity, Makerere University, P.O. Box 7062, Kampala, Uganda.

${ }^{2}$ Africa Innovations Institute, P.O. Box 34981, Kampala, Uganda.

${ }^{3}$ Dept of Veterinary Parasitology, College of Veterinary Medicine, Animal Resources and Biosecurity, Makerere University, Kampala, Uganda.

${ }^{4}$ Dept of Nutrition, Hanyang University, Seoul, Korea.

${ }^{5}$ Natural Resources Institute, University of Greenwich, Medway Campus,

Central Avenue, Chatham Maritime, Kent ME4 4TB, UK.

Received: 23 March 2015 Accepted: 4 June 2015

\section{Published online: 29 June 2015}

\section{References}

Adger, Neil W. 2006. Vulnerability. Global Environmental Change 16: 268-281.

Afrll. 2011. Adaptation to the impact of climate variability on food and health security in the cattle corridor of Uganda. In Project Technical Report by Africa Innovations Institute (www.afrii.org), in archives.

Ahamad, Mazbahul Golam, and Rezai Karim Khondker. 2010. Climate risks, seasonal food insecurity and consumption coping strategies: Evidences from a micro-level study from Northern Bangladesh. Economics Bulletin 30(2): 1444-1459.

Benson, Todd, and Samuel Mugarura. 2010. Livestock development planning in Uganda: Identification of areas of opportunity and challenge, International Food Policy Research Institute: IFPRI Discussion Paper 01008.

Daniel Maxwell, Patrick Webb, Jennifer Coates, and James Wirth. 2008b. Rethinking food security in humanitarian response. In Food Security Forum. Rome: Science and Policy, Tufts University.

FAO. 2002. FIVIMS tools and tips: Understanding food insecurity and vulnerability. In Food insecurity and vulnerability information mapping systems. Rome: FAO.

FAO. 2003. Trade reforms and food security: Conceptualising the linkages. FAO, Rome. http://www.fao.org/docrep/005/y4671e/y4671e00.htm.

FEWSNET. 2010. Livelihood mapping and zoning exercise: Uganda. In A special report by the Famine and Early Warning System Network, ed. Stephen Browne and Laura Glaeser. USA: USAID.

Løvendal, Christian Romer, and Marco Knowles. 2005. Tomorrow's hunger: A framework for analysing vulnerability to food insecurity, ESA Working Paper No. 05-07. Agricultural and Development Economics Division, FAO. http://www.fao.org/docrep/008/af140e/af140e00.HTM.

Maxwell, Daniel, Clement Ahiadekeb, Carol Levinc, Margaret Armar-Klemesud, Sawudatu Zakariahd, and Grace Mary Lamptey. 1999. Alternative food-security indicators: Revisiting the frequency and severity of 'coping strategies'. Food Policy 24: 411-429.

Maxwell, Daniel, Watkins Ben, Wheeler Robin, and Collins Greg. 2003. The coping strategy index: A tool for rapidly measuring food security and the impact of food aid programmes in emergencies. Field methods manual. Nairobi: CARE \& WFP

Maxwell, Daniel, Richard Caldwell, and Mark Langworthy. 2008. Measuring food insecurity: Can an indicator based on localized coping behaviors be used to compare across contexts? Food Policy 33: 533-540.

Mjonono, Mfusi, Mjabuliseni Ngidi, and Sheryl L Hendriks. 2009. Investigating household food insecurity coping strategies and the impact of crop production on food security using coping strategy index (CSI). In 17th International Farm Management Congress, Bloomington/Normal, Illinois, USA.

Morton, John. 2007. The impact of climate change on smallholder and subsistence agriculture. PNAS 104(50): 19680-19685.

NAPA. 2007. Climate change: Uganda National Adaptation Programmes of Action. Kampala: Government of Uganda. http://unfccc.int/resource/docs/ napa/uga01.pdf.

Nimusiima, Alex, CPK Basalirwa, JGM Majaliwa, W Otim-Nape, J Okello-Onen, C Rubaire-Akiikii, J Konde-Lule, and S Ogwal-Byenek. 2013. Nature and dynamics of climate variability in the Uganda cattle corridor. African Journal of Environmental Science and Technology 7(8): 770-782.

O'Laughlin, Bridget. 1999. In defence of the household: Marx, gender and the utilitarian impasse. In ISS Working Paper Series/General Series, Vol 289. Netherlands: Erasmus University Rotterdam.

Renzaho, Andre M N, and David Mellor. 2009. Food security measurement in cultural pluralism: Missing the point or conceptual misunderstanding? Nutrition 26(1): 1-9.

\section{Submit your manuscript to a SpringerOpen ${ }^{\odot}$ journal and benefit from:}

- Convenient online submission

- Rigorous peer review

- Immediate publication on acceptance

- Open access: articles freely available online

- High visibility within the field

- Retaining the copyright to your article

Submit your next manuscript at $>$ springeropen.com 